\title{
Passive degassing at Nyiragongo (D.R. Congo) and Etna (Italy) volcanoes
}

\author{
Sergio Calabrese ${ }^{* 1}$, Sarah Scaglione ${ }^{1}$, Silvia Milazzo ${ }^{1}$, Walter D’ Alessandro ${ }^{2}$, \\ Nicole Bobrowski ${ }^{3}$, Giovanni B. Giuffrida ${ }^{2}$, Dario tedesco ${ }^{4,5}$, Francesco Parello ${ }^{1}$, \\ MATHIEW YaLiRE $^{5}$ \\ 1 Dipartimento di Scienze della Terra e del Mare (DiSTeM), University of Palermo \\ - Italy, 2 Istituto Nazionale di Geofisica e Vulcanologia (INGV) Palermo - Italy, 3 \\ University of Heidelberg, Germany, 4 Seconda Università degli Studi di Napoli, \\ Caserta, Italy, 5 Observatoire Volcanologique de Goma, D.R. Congo
}

*sergio.calabrese@gmail.com

\begin{abstract}
Volcanoes are well known as an impressive large natural source of trace elements into the troposphere. Etna (Italy) and Nyiragongo (D.R. Congo) are two stratovolcanoes located in different geological settings, both characterized by persistent passive degassing from their summit craters. Here, we present some results on trace element composition in volcanic plume emissions, atmospheric bulk deposition (rainwater) and their uptake by the surrounding vegetation, with the aim to compare and identify differences and similarities between these two volcanoes. Volcanic emissions were sampled by using active filter-packs for acid gases (sulfur and halogens) and specific teflon filters for particulates (major and trace elements). The environmental impact of the volcanogenic deposition in the area surrounding of the crater rims was investigated by using different sampling techniques: bulk rain collectors' gauges were used to collect atmospheric bulk deposition, and biomonitoring was carried out to collect gases and particulates by using endemic plant species. The estimates of the trace element fluxes confirm that Etna and Nyiragongo are large sources of metals into the atmosphere, especially considering their persistent state of passive degassing. The large amount of emitted trace elements is clearly reflected on the chemical composition of rainwater collected at the summit areas both for Etna and Nyiragongo. Moreover, the biomonitoring results highlight that bioaccumulation of trace elements is extremely high in the proximity of the crater rim and decreases with the distance from the active craters.
\end{abstract}

\section{INTRODUCTION}

$\mathrm{V}$ olcanic emissions represent one of the most important natural sources of trace elements into the atmosphere (e.g. As, $\mathrm{Cd}, \mathrm{Cu}, \mathrm{Hg}, \mathrm{Pb}, \mathrm{Sb}, \mathrm{Tl}$ and $\mathrm{Zn}$ ), sequentially influencing the other geochemical spheres (hydrosphere, pedosphere and biosphere). Etna (Italy) and Nyiragongo (D.R. Congo) are two of the major gas emitters on Earth [Burton et al., 2013]. Although located in different geological settings, both are characterized by persistent passive degassing from their summit craters. Nyiragongo is situated in the western side of the East-African Rift in the D.R. Congo. It is famous for the currently largest lava lake on Earth and its lava contains very low amounts of silica (down to $36 \% \mathrm{SiO}_{2}$ ) but has a high potassium and sodium content summing up to about $12 \%$ [Alba et al., 2002]. Etna is situated close to the African and 
ANNALS OF GEOPHYSICS, Fast Track 2, 2014

European plate margins, on Sicily, Italy and shows more evolved basaltic lava than Nyiragongo with about $47 \% \quad \mathrm{SiO}_{2}$ content [Viccaro and Cristofolini, 2008]. Etna is degassing from 4 active summit craters each showing an individual chemical composition. Both volcanoes are characterized by degassing features from the mantle and particular high bromine emissions [Bobrowski et al., 2014]. Due to its easier accessibility, Mt. Etna is one of the most studied volcanic systems. Its metal emission through the plume has been estimated since 1976 [Buat-Menard and Arnold 1978] and many published data have been recently reviewed in Calabrese et al. [2011a]. On the contrary, no data on metal fluxes from Nyiragongo have been published until now. In the present study the first data on major and trace metal emissions from Nyiragongo were compared to those of Mt. Etna. The Nyiragongo samples were taken during a short measurement campaign in December 2011. Furthermore, to get insights on the impact of the volcanic emissions of these two volcanoes on the surrounding environment, rainwater samples (bulk deposition) and leaves of endemic pioneer plants were collected and analysed for the same elements.

\section{METHODS}

Volcanic gas and particle emissions were sampled simultaneously using active filter-packs for acid gases $\left(\mathrm{SO}_{2}, \mathrm{HCl}\right.$ and $\left.\mathrm{HBr}\right)$ and specific teflon filters for particles (major and trace elements) (Fig.1). The volcanogenic deposition in the surroundings of the crater rims was investigated by using different sampling techniques (Fig.1): rain gauge collectors were used for atmospheric bulk deposition; biomonitoring techniques were carried out to analyse the uptake of gases and particle by endemic plant (Senecio sp.).
The elemental fluxes were calculated by the following expression:

$\Phi X=|X| /|S| \Phi S$

where $\Phi X$ is the element flux $\left(\mathrm{t} \mathrm{d}^{-1}\right),|\mathrm{X}| /|\mathrm{S}|$ is the element-to-sulfur mass ratios, and $\Phi S$ is the flux of sulfur $\left(\mathrm{t} \mathrm{d}^{-1}\right)$. Sulfur fluxes from Nyiragongo were obtained from the permanent Network for Observation of Volcanic and Atmospheric Change (NOVAC) [Arellano et al., 2013].
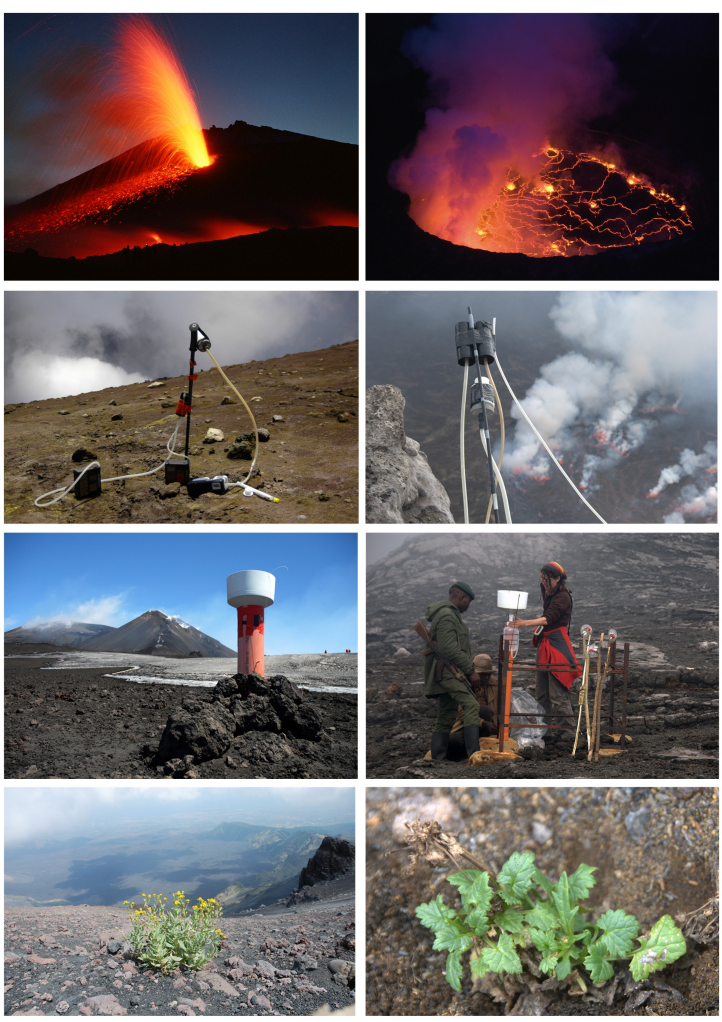

Figure 1: Sampling at Mt. Etna (on the left) and Nyiragongo (on the right). From the top: volcanic activity; plume sampling; the bulk collectors; vegetation for biomonitoring.

In order to compare the plume, rainwater and vegetation data in both volcanoes, the enrichment factors were calculated as:

$\mathrm{EFx}=(\mathrm{Cx} / \mathrm{Cr})$ sample $/(\mathrm{Cx} / \mathrm{Cr}) \mathrm{rm}$ 
where $(\mathrm{Cx} / \mathrm{Cr})$ sample is the concentrations ratio of an element $x$ normalized to a reference element $(r)$ in the sample, and $(\mathrm{Cx} / \mathrm{Cr}) \mathrm{rm}$ is the corresponding ratio in a reference material (rm). We used $\mathrm{Al}$ as normalizing element and the composition of the continental crust [Wedepohl, 1995] as reference material. Detailed description of sampling and analytical methods is given as electronic annex (Annex1).

\section{RESULTS}

The analytical results (plume, bulk deposition and leaves) and metal flux calculations are reported as electronic annex (Annex 2).

\section{Plume composition and trace metal fluxes}

The most abundant metals in aerosols sampled at the rim of the two volcanoes were $\mathrm{K}, \mathrm{Al}, \mathrm{Ca}$, $\mathrm{Fe}, \mathrm{Mg}, \mathrm{Cu}, \mathrm{Zn}$ and $\mathrm{Ti}$ (median values ranging from 0.1 to $25 \mu \mathrm{g} / \mathrm{m}^{3}$ ), followed by several trace metals including potentially toxic elements (e.g. Pb, V, As, Tl, Mo, Cd) ranging from 0.001 to $0.1 \mu \mathrm{g} / \mathrm{m}^{3}$. For both volcanic systems the measured absolute atmospheric concentrations span over many orders of magnitude mainly depending on the dilution of the plume during sampling. To compare the data of the two volcanoes, all concentrations were normalized to the $S$ concentration measured at the same time. The obtained values are shown in Fig. 2 and the median values are summarised in the annex 1 . Also the obtained metal/S ratios span over wide ranges. Considering the ratios between the median value of Etna and that of Nyiragongo, we can subdivide the analysed elements in 3 groups: i) metal/S ratios < 0.1 ( $\mathrm{Cu}, \mathrm{Bi}, \mathrm{Al}, \mathrm{Cr}, \mathrm{Pb}, \mathrm{Rb}, \mathrm{Cs}, \mathrm{Zn}$ and $\mathrm{Mg})$; ii) between 0.1 and $10(\mathrm{~K}, \mathrm{Ba}, \mathrm{Ca}, \mathrm{Fe}, \mathrm{Ti}, \mathrm{Mo}, \mathrm{Mn}$, Cd, As, Sr and V); iii) >10 (Tl).

The estimated elemental fluxes (Fig. 3) confirm that Etna and Nyiragongo are large sources of metals to the atmosphere, also considering their persistent state of passive degassing [Hinkley et al., 1999; Henley and Berger, 2013]. Enrichment factors calculated for both volcanoes showed high values for $\mathrm{Bi}, \mathrm{Cd}, \mathrm{Pb}, \mathrm{As}$ and Mo (Fig. 4), highlighting the affinity of theses element to the volatiles. The most significant difference is the higher $\mathrm{Tl}$ enrichment of Etna plume respect to the Nyiragongo.

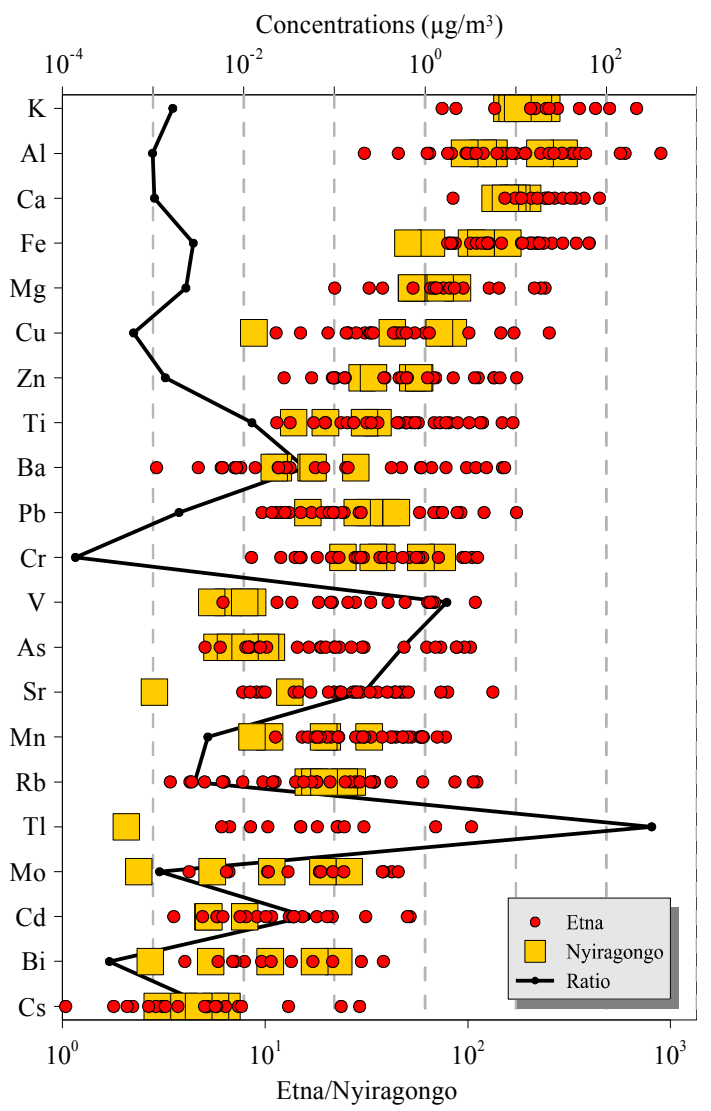

Figure 2: Metal/S ratios in the plumes of the two volcanoes. Elements are ordered basing on decreasing median values of Etna.

\section{Rainwater}

The large amount of trace elements emitted from volcanoes has a strong impact on the chemical composition of rainwater collected at the summit areas of both volcanoes. Samples have low $\mathrm{pH}$ values $(<2)$ and high concentra- 
ANNALS OF GEOPHYSICS, Fast Track 2, 2014

tions of toxic metals. Concentrations of major and trace elements in rainwater were obtained by direct sampling of bulk deposition at the crater rim.

Compared to rainwater compositions measured at Goma and Mt. Intraleo, $20 \mathrm{~km}$ and 7.5 $\mathrm{km}$ from the crater of Nyiragongo and Etna, respectively, [Calabrese et al., 2011a; Cuoco et al., 2013a; Calabrese et al., 2014] concentrations were generally many orders of magnitudes higher. Major elements have been previously analyzed in rainwater samples collected around the Nyiragongo crater by Cuoco et al., [2013b] and our results fall at the higher end of their range. The enrichment factors of rainwaters confirm that many of the volatile trace metals, enriched in the plume strongly influence the atmospheric deposition close to the craters (Fig.4). The fingerprint of volcanic input on rainwater is characterized by $\mathrm{Bi}, \mathrm{Tl}, \mathrm{Cd}$, $\mathrm{Cu}$ and As.

\section{Biomonitoring survey}

Chemical composition of Senecio leaves collected on the summit of Nyiragongo clearly reflects the fingerprint of volcanic emissions. Leaves of 6 plants were taken on the upper part of Nyiragongo on December 2011. All the samples collected at the crater rim show high concentrations with respect to the local background (about $20 \mathrm{~km}$ from the crater), both for refractory elements (like $\mathrm{Al}, \mathrm{Ti}, \mathrm{V}, \mathrm{Fe}, \mathrm{Th}, \mathrm{U}$ and Lanthanides) and volatile elements (e.g. As, Se, Te, Bi). Plants of the same genus collected on Mt. Etna (in 2009) showed also a strong accumulation capacity revealing the input of volcanogenic elements and confirming that Senecio is a good biomonitor in volcanic environments [Calabrese et al., 2011b]. Both plants in the two volcanic systems revealed good correlations comparing many elements. The slight differences in the elemental ratios between the two systems probably reflect the differences in the plume ratios.

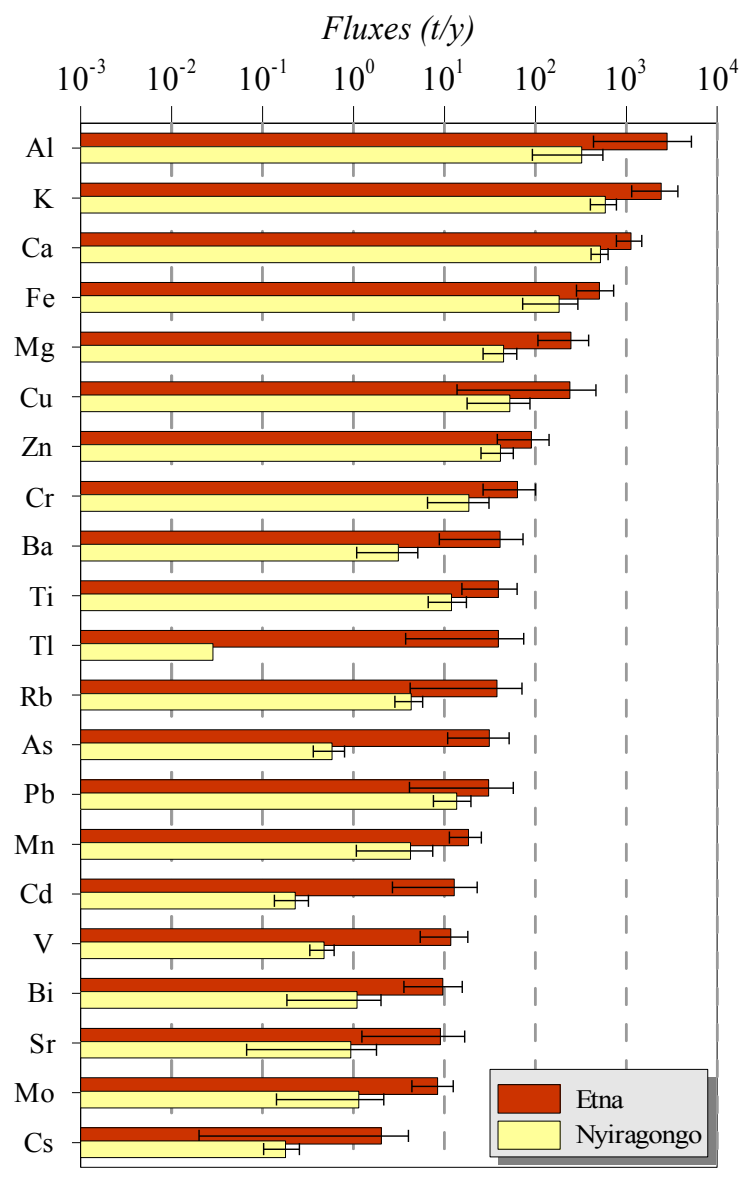

Figure 3: Comparison of Trace element fluxes of Etna and Nyiragongo. Data gained by teflon filter measurements at the crater rims.

\section{Discussion}

As previously highlighted by many authors [Aiuppa et al., 2003; Mather et al., 2003; Calabrese et al., 2011a], the chemical composition of the volcanic aerosol particles is characterized by two main components: one is related to the silicic component produced by magma bursting and fragmentation and the second is related to the gas volatile phase $\left(\mathrm{H}_{2} \mathrm{O}, \mathrm{CO}_{2}\right.$, $\mathrm{SO}_{2}, \mathrm{HCl}, \mathrm{HF}$ ) and transported to the atmosphere mainly as hydro-soluble salts and/or in gaseous form in some cases. At Mt. Etna and 
Nyiragongo the first component is characterised by $\mathrm{Al}, \mathrm{Fe}, \mathrm{Mg}, \mathrm{Ca}, \mathrm{K}$ and trace elements like $\mathrm{Cr}, \mathrm{La}, \mathrm{Ti}$, and $\mathrm{V}$ while the second component is dominated by $\mathrm{As}, \mathrm{Bi}, \mathrm{Cd}, \mathrm{Cs}, \mathrm{Cu}, \mathrm{Pb}$, $\mathrm{Tl}$. The strong impact of volcanic emission on the surrounding environment has been assessed for many volcanic systems [Delmelle, 2003]. On Etna its fingerprint has been evidenced in many geochemical spheres: atmo- sphere [Aiuppa et al., 2004], meteoric depositions [Bellomo et al., 2007; Calabrese et al., 2011a], soils [Floor et al., 2011], vegetation [Martin et al., 2009]. Similarly, at Nyiragongo rainwater and vegetation samples reflect the chemical composition of the plume, which sequentially affects the deposition and the vegetation in the surroundings of the crater.

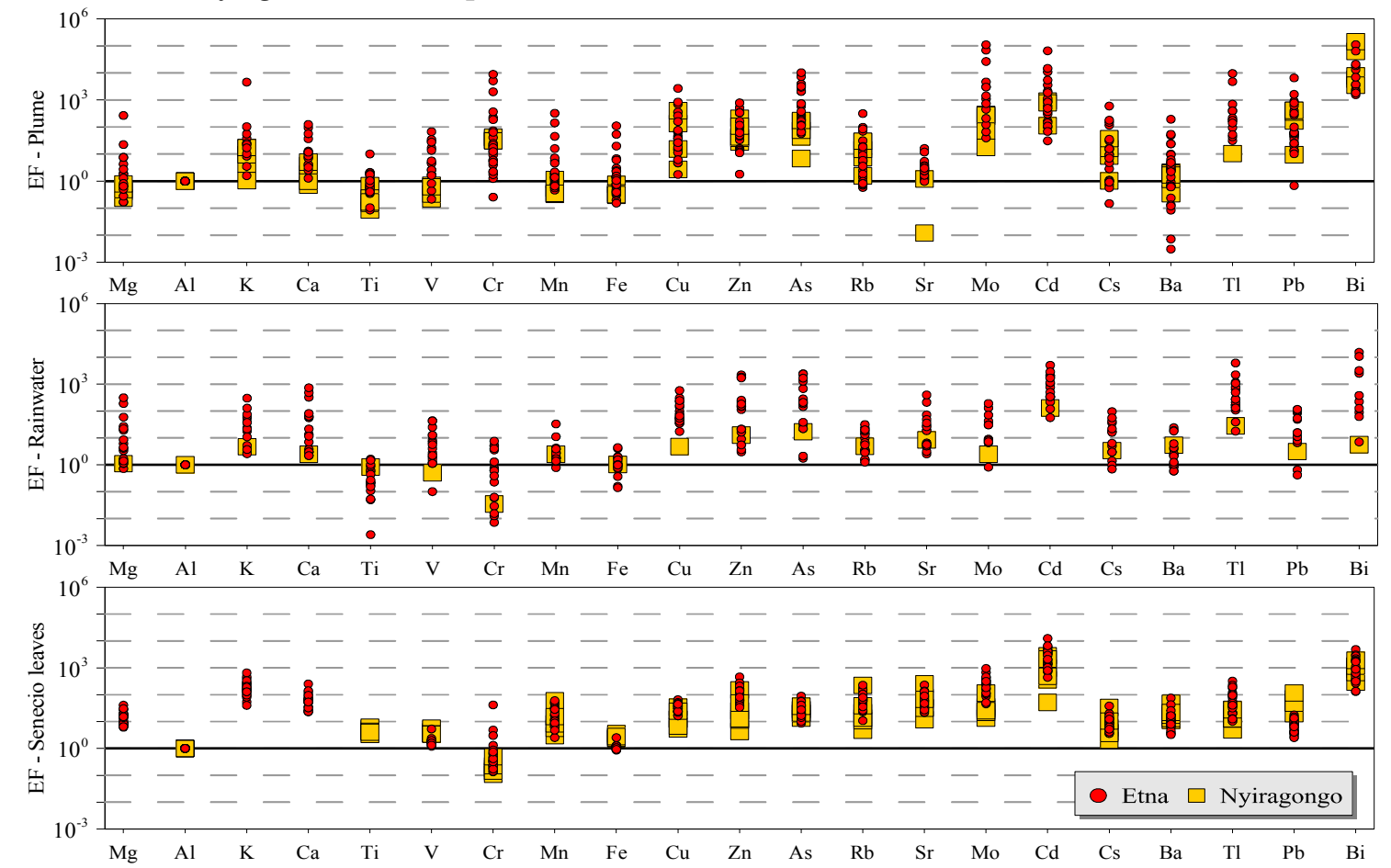

Figure 4: Comparison between Etna and Nyiragongo by using the enrichment factors (EF - see text).

\section{REFERENCES}

[Aiuppa et al., 2003] Aiuppa A., Dongarrà G., et al. (2003). Degassing of trace volatile metals during the 2001 eruption of Etna. In: Volcanism and the Earth's Atmosphere (Robock A., Oppenheimer C. eds.) Geoph. Monograph 139. [Aiuppa et al., 2004] Aiuppa A., D'Alessandro et al. (2004). Volcanic plume monitoring at Mount Etna by diffusive (passive) sampling. J. Geophys.l Res. 109, D21308

[Alba et al., 2002] Alba P.S., Capaccioni B., et al. (2002). Petrographic and geochemical features of the 2002 Nyiragongo lava flows. Acta Vulcanol. 14, 63-66.

[Arellano et al., 2013] Arellano S., Galle B., et al. (2013). Intensity, magnitude and impact of degassing activity of Nyiragongo volcano during 2004-2013, AVCOR, Gisenyi, Rwanda, 2013 [Bellomo et al., 2007] Bellomo S., Aiuppa A., et al. (2007). Environmental impact of magmatic fluorine emission in the Mt. Etna area. J. Volcanol. Geotherm. Res. 165, 87-101

[Bobrowski et al., 2014] Bobrowski N., von 
ANNALS OF GEOPHYSICS, Fast Track 2, 2014

Glasow R., et al. (2014). Gas molar ratio of $\mathrm{BrO} / \mathrm{SO}_{2}$ in the plume emission strength and evolution of the Mt. Nyiragongo in comparison to Mt. Etna, J. Geophys. Res. (subm.)

[Buat-Menard and Arnold, 1978] Buat-Menard P., Arnold M. (1978). The heavy metal chemistry of atmospheric particulate matter emitted by Mount Etna volcano. Geophys. Res. Lett. 5, 245-248.

[Burton et al., 2013] Burton M.R., Sawyer G.M., et al. (2013). Deep Carbon Emissions from Volcanoes. Rev. Mineral. Geoche. 75, 323-354.

[Calabrese et al., 2011a] Calabrese S., Aiuppa A., et al. (2011). Atmospheric sources and sinks of volcanogenic elements in a basaltic volcano (Etna, Italy), Geochim. Cosmochim. Acta 75:7401-7425.

[Calabrese et al., 2011b] Calabrese S., Bagnato E., et al. (2011). Impact of Volcanic Emissions on Trace Elements Contents Measured in Endemic Plants at Mt. Etna (Italy). Misc. INGV 2011, n.9

[Calabrese et al., 2014] Calabrese S., Scaglione S., et al. (2014). Passive degassing at Nyiragongo (D.R. Congo) and Etna (Italy) volcanoes: the chemical characterization of the emissions and assessment of their uptake of trace elements emissions on the local environment. Geophys. Res. Abstr. 16, EGU2014-6783. [Cuoco et al., 2013a] Cuoco E., Tedesco D., et al. (2013). Impact of volcanic plume emissions on rain water chemistry during the January 2010 Nyamuragira eruptive event: Implications for essential potable water resources. J. Haz. Mat., 244-245, 570-581.

[Cuoco et al., 2013b] Cuoco E., Spagnuolo A., et al. (2013). Impact of volcanic emissions on rainwater chemistry: The case of $\mathrm{Mt}$. Nyiragongo in the Virunga volcanic region (DRC). J. Geochem. Explor., 125, 69-79

[Delmelle, 2003] Delmelle, P. (2003). Environmental impacts of tropospheric volcanic gas plumes. In: Oppenheimer, C., Pyle, D.M.,
Barclay, J. (Eds.). Volcanic degassing. Geol. Soc., London, Spec. Publ., 213, 381-399.

[Floor et al., 2011] Floor G.H., Calabrese S., at al. (2011). Selenium mobilization in soils due to volcanic derived acid rain: An example from Mt Etna volcano, Sicily. Chem. Geol. 289, 235244.

[Henley et al., 2013] Henley R.W., Berger B.R., (2013). Nature's refineries - Metals and metalloids in arc volcanoes. Earth-Sci. Reviews, 125, 146-170

[Hinkley et al., 1999] Hinkley T.K., Lamothe P.J., et al. (1999). Metal emissions from Kilauea, and a suggested revision of the estimated worldwide metal output by quiescent degassing of volcanoes. Earth Planet. Sci. Lett. 170, 315-325.

[Martin et al., 2009] Martin R.S., Mather T.A., et al. (2009). Sweet chestnut (Castanea sativa) leaves as a bio-indicator of volcanic gas, aerosol and ash deposition onto the flanks of Mt. Etna in 2005-2007. J. Volcanol. Geotherm. Res. 179, 107-119

[Mather et al., 2003] Mather T.A., Pyle D.M., et al. (2003). Tropospheric volcanic aerosol, in volcanism and the Earth's atmosphere. In: Volcanism and the Earth's Atmosphere (Robock A., Oppenheimer C. eds.) Geophysical Monograph 139, 189-212.

[Viccaro and Cristofolini, 2008] Viccaro M., Cristofolini R.. (2008). Nature of mantle heterogeneity and its role in the short-term geochemical and volcanological evolution of Mt. Etna (Italy). Lithos 105, 272-288.

[Wedepohl, 1995] Wedepohl K.H. (1995). The composition of the continental crust. Geochim. Cosmochim. Acta 59, 1217-1232. 